\title{
Assessment of sea ice simulations in the CMIP5 models
}

\author{
Q. Shu ${ }^{1,2}$, Z. Song ${ }^{1,2}$, and F. Qiao ${ }^{1,2}$ \\ ${ }^{1}$ First Institute of Oceanography, State Oceanic Administration, Qingdao, 266061, China \\ ${ }^{2}$ Key Lab of Marine Science and Numerical Modeling, SOA, Qingdao, 266061, China \\ Correspondence to: F. Qiao (qiaofl@ fio.org.cn)
}

Received: 23 May 2014 - Published in The Cryosphere Discuss.: 27 June 2014

Revised: 1 December 2014 - Accepted: 9 January 2015 - Published: 20 February 2015

\begin{abstract}
The historical simulations of sea ice during 1979 to 2005 by the Coupled Model Intercomparison Project Phase 5 (CMIP5) are compared with satellite observations, Global Ice-Ocean Modeling and Assimilation System (GIOMAS) output data and Pan-Arctic Ice Ocean Modeling and Assimilation System (PIOMAS) output data in this study. Forty-nine models, almost all of the CMIP5 climate models and earth system models with historical simulation, are used. For the Antarctic, multi-model ensemble mean (MME) results can give good climatology of sea ice extent (SIE), but the linear trend is incorrect. The linear trend of satellite-observed Antarctic SIE is $1.29( \pm 0.57) \times 10^{5} \mathrm{~km}^{2} \mathrm{decade}^{-1}$; only about $1 / 7$ CMIP5 models show increasing trends, and the linear trend of CMIP5 MME is negative with the value of -3.36 $( \pm 0.15) \times 10^{5} \mathrm{~km}^{2} \mathrm{decade}^{-1}$. For the Arctic, both climatology and linear trend are better reproduced. Sea ice volume (SIV) is also evaluated in this study, and this is a first attempt to evaluate the SIV in all CMIP5 models. Compared with the GIOMAS and PIOMAS data, the SIV values in both the Antarctic and the Arctic are too small, especially for the Antarctic in spring and winter. The GIOMAS Antarctic SIV in September is $19.1 \times 10^{3} \mathrm{~km}^{3}$, while the corresponding Antarctic SIV of CMIP5 MME is $13.0 \times 10^{3} \mathrm{~km}^{3}$ (almost $32 \%$ less). The Arctic SIV of CMIP5 in April is $27.1 \times 10^{3} \mathrm{~km}^{3}$, which is also less than that from PIOMAS SIV $\left(29.5 \times 10^{3} \mathrm{~km}^{3}\right)$. This means that the sea ice thickness simulated in CMIP5 is too thin, although the SIE is fairly well simulated.
\end{abstract}

\section{Introduction}

The Coupled Model Intercomparison Project Phase 5 (CMIP5) provides a very useful platform for studying climate change. Simulations and projections by more than 60 state-of-the-art climate models and earth system models are archived under CMIP5. Assessment of the performance of CMIP5 outputs is necessary for scientists to decide which model outputs to use in their research and for modeldevelopers to improve their models. Here, we focus on the assessment of sea ice simulations under the CMIP5 historical experiment. The CMIP5 data portal contains sea ice outputs from 49 coupled models. Many of these CMIP5 sea ice simulations have been evaluated and several valuable studies have been published.

For the Antarctic, the main problem of the CMIP5 models is their inability to reproduce the observed slight increase of sea ice extent (SIE). Turner et al. (2013) first assessed CMIP5 Antarctic SIE simulations using 18 models, and summarized that the majority of these models have too little SIE at the minimum sea ice period of February, and the mean of these 18 models' SIE shows a decreasing trend over 1979-2005, opposite to the satellite observation that exhibits a slight increasing trend. Polvani et al. (2013) used four CMIP5 models to study the cause of observed Antarctic SIE increasing trend under the conditions of increasing greenhouse gases and stratospheric ozone depletion. They concluded that it is difficult to attribute the observed trend in total Antarctic sea ice to anthropogenic forcing. Zunz et al. (2013) suggested that the model Antarctic sea ice internal variability is an important metric to evaluate the observed positive SIE trend. Using simulations from 25 CMIP5 models, Mahlstein et al. (2013) pointed out that internal sea ice variability is large in the Antarctic region and that both the observed and 
simulated trends may represent natural variation along with external forcing.

For the Arctic, CMIP5 models offer much better simulations. Stroeve et al. (2012) evaluated CMIP5 Arctic SIE trends using 20 CMIP5 models. They found that the seasonal cycle of SIE was well represented, and that the simulated SIE decreasing trend was more consistent with the observations over the satellite era than that of CMIP3 models but still smaller than the observed trend. They also noted that the spread in projected SIE through the 21st century from CMIP5 models is similar to that from CMIP3 models. Massonnet et al. (2012) examined 29 CMIP5 models and provided several important metrics to constrain the projections of summer Arctic sea ice projection. Liu et al. (2013) also pointed out that CMIP5 projections have large inter-model spread, but they also found that they could reproduce consistent Arctic ice-free time by reducing the large spread using two different approaches with 30 CMIP5 models.

Most evaluations of CMIP5 sea ice simulation in these studies are based only on some of CMIP5 models' outputs with some metrics, because other CMIP5 model outputs were not yet submitted. By now, all the CMIP5 participants have finished their model runs and submitted their model outputs. So, here we will evaluate all CMIP5 sea ice simulations with more metrics in both the Antarctic and the Arctic in an attempt to provide the community a useful reference. Generally speaking, our study shows the following: that the performance of Arctic sea ice simulation is better than that of Antarctic sea ice simulation, that sea ice extent simulation is better than sea ice volume simulation, and that mean state simulation is better than long-term trend simulation. If we want to get a similar result with all CMIP5 sea ice simulations, the number of models during analysis should be more than 22 .

The rest of the paper is structured as follows. Section 2 presents sea ice data and analysis methodology used in this study. Model assessment is given in Sect. 3. Conclusions and discussion are provided in Sect. 4.

\section{Data and methodology}

Sea ice simulations of CMIP5 historical runs from 49 CMIP5 coupled models are now available. Monthly sea ice concentration (SIC) and sea ice thickness from these models are used in this study. These outputs are published by the Earth System Grid Federation (ESGF) (http://pcmdi9. llnl.gov/esgf-web-fe/) by each institute that is responsible for its model. Although there are several ensemble realizations of each CMIP5 model, the standard deviation between different ensemble realizations of each model is small (Turner et al., 2013; Table 1). We also plot the spatial patterns of SIC in February (Fig. S1 in the Supplement) and September (Fig. S2) from different ensemble realizations from GISS-E2-R which has 15 ensemble realizations and more ensemble realizations than most CMIP5 models. We can see that the standard deviation between different ensemble realizations from the same model is comparable. So, here we only choose the first realization of each model for the analysis. CMIP5 historical runs cover the period from 1850 to 2005 , but the continuous sea ice satellite record only started in 1979; so the period of 1979-2005 is chosen for the following analysis. Monthly satellite-observed SIC is used in this study, which is based on the National Aeronautics and Space Administration (NASA) team algorithm (Cavalieri et al., 1996) provided by the National Snow and Ice Data Centre (NSIDC) (http://nsidc.org/data/ seaice/). Satellite-observed sea ice extent used here is also from NSIDC (ftp://sidads.colorado.edu/DATASETS/NOAA/ G02135/). Sea ice volume (SIV) is an important index for assessment of sea ice simulation, although direct observations of SIV are very limited. SIV in the Antarctic used here is from the Global Ice-Ocean Modeling and Assimilation System (GIOMAS) (http://psc.apl.washington.edu/zhang/ Global_seaice/index.html). SIV in the Arctic is from PanArctic Ice Ocean Modeling and Assimilation System (PIOMAS) (http://psc.apl.washington.edu/wordpress/research/ projects/arctic-sea-ice-volume-anomaly/). Note that SIV data from GIOMAS and PIOMAS are not observations but model simulations with data assimilation. Stroeve et al. (2014) compared observed sea ice thickness data in the Arctic with that of PIOMAS, and concluded that PIOMAS provides useful estimates of Arctic sea ice thickness and SIV, and that it can be used to assess the CMIP5 models' performances. But there are not enough observations to validate GIOMAS sea ice thickness in the Antarctic. The climatology and linear trends of CMIP5-simulated SIE, SIC and SIV are compared with satellite observations and GIOMAS and PIOMAS data. CMIP5 simulated SIE is computed as the total area of all grid cells where SIC exceeds $15 \%$. SIV is computed as the sum of the product of SIC, the area of grid cell and sea ice thickness of each grid cell. All gridded SIC and sea ice thickness are re-gridded onto $1.0^{\circ}$ longitude by $1.0^{\circ}$ latitude grids before the analysis is performed. In this study, spring is from March to May for the Arctic, and from September to November for the Antarctic. Summer, autumn and winter are defined accordingly.

\section{Results}

We select several metrics to assess the sea ice simulations in CMIP5 models. Mean state, seasonal cycle, the model internal variability, linear trends and simulation errors are used. For the Arctic sea ice, model mean state and seasonal cycle are important to Arctic sea ice projection (Massonnet et al., 2012). For the Antarctic sea ice, the model internal variability is an important metric to evaluate the observed positive SIE trend (Zunz et al., 2013). Annual mean SIE, SIE amplitude, standard deviation of detrended SIE anomaly (SIE 
Table 1. Antarctic sea ice metrics in CMIP5 models, satellite observations and GIOMAS data set. Column (a) is mean annual SIE in million $\mathrm{km}^{2}$. Column (b) is monthly SIE amplitude in million $\mathrm{km}^{2}$. Column (c) is standard deviation of detrended monthly SIE anomaly in million $\mathrm{km}^{2}$. Column (d) is linear trend in monthly SIE in $10^{5} \mathrm{~km}^{2}$ decade -1 , and the value in parentheses is $95 \%$ confidence level. Column (e) is monthly SIE root mean square error in million $\mathrm{km}^{2}$. Column (f) is mean annual SIV in $10^{3} \mathrm{~km}^{3}$. Column (g) is monthly SIV amplitude in $10^{3} \mathrm{~km}^{3}$. Column (h) is standard deviation of detrended monthly SIV anomaly in $10^{3} \mathrm{~km}^{3}$. Column (i) is linear trend in monthly SIV in $10^{3} \mathrm{~km}^{3}$ decade $^{-1}$, and the value in parentheses is $95 \%$ confidence level. Column (j) is monthly SIV root mean square error in $10^{3} \mathrm{~km}^{3}$. The models with bold metric number have special performances, and details can be found in the text.

\begin{tabular}{|c|c|c|c|c|c|c|c|c|c|c|}
\hline $\begin{array}{l}\text { Data sources or CMIP5 } \\
\text { models }\end{array}$ & (a) & (b) & (c) & (d) & (e) & (f) & (g) & (h) & (i) & (j) \\
\hline Observations or GIOMAS & 11.94 & 15.70 & 0.40 & $1.29(0.57)$ & - & 11.02 & 17.17 & 0.63 & $0.45(0.09)$ & - \\
\hline Multi-model ensemble mean (MME) & 11.50 & 15.46 & 0.11 & $-3.36(0.15)$ & 0.71 & 7.73 & 10.31 & 0.10 & $-0.36(0.01)$ & 4.20 \\
\hline ACCESS 1.0 & 12.10 & 19.12 & 0.59 & $-1.72(0.83)$ & 1.57 & 6.30 & 11.35 & 0.43 & $-0.15(0.06)$ & 5.20 \\
\hline ACCESS1.3 & 14.24 & 15.77 & 0.54 & $-0.97(0.77)$ & 2.31 & 10.71 & 9.78 & 0.67 & $-0.03(0.09)$ & 2.75 \\
\hline BCC-CSM1.1 & 13.42 & 19.32 & 1.27 & $2.71(1.78)$ & 2.11 & 7.13 & 11.51 & 0.92 & $0.09(0.13)$ & 4.41 \\
\hline BCC-CSM1-1-M & 12.26 & 18.86 & 1.06 & $-20.03(1.49)$ & 1.52 & 5.65 & 9.98 & 0.71 & $-1.20(0.10)$ & 5.92 \\
\hline BNU-ESM & 20.60 & 23.46 & 0.82 & $-9.60(1.15)$ & 9.19 & 18.49 & 22.48 & 0.87 & $-2.03(0.12)$ & 7.89 \\
\hline CanCM4 & 14.65 & 20.58 & 0.74 & $-2.79(1.03)$ & 3.40 & 3.09 & 4.81 & 0.28 & $-0.06(0.04)$ & 9.21 \\
\hline CanESM2 & 14.69 & 20.64 & 0.96 & $-7.74(1.35)$ & 3.42 & 3.09 & 4.82 & 0.40 & $-0.15(0.06)$ & 9.22 \\
\hline CCSM4 & 18.37 & 13.70 & 0.58 & $-7.34(0.82)$ & 6.64 & 19.34 & 18.63 & 1.12 & $-1.56(0.16)$ & 8.34 \\
\hline CESM1-BGC & 17.67 & 14.05 & 0.49 & $-6.68(0.69)$ & 5.93 & 18.28 & 18.31 & 0.91 & $-1.19(0.13)$ & 7.28 \\
\hline CESM1-CAM5 & 14.06 & 14.78 & 0.47 & $-5.52(0.66)$ & 2.58 & 11.22 & 16.05 & 0.58 & $-0.97(0.08)$ & 1.13 \\
\hline CESM1-CAM5-1-FV2 & 13.01 & 14.11 & 0.58 & $-3.16(0.82)$ & 1.77 & 9.96 & 14.12 & 0.74 & $-0.22(0.10)$ & 1.89 \\
\hline CESM1-FASTCHEM & 17.86 & 13.42 & 0.60 & $-8.78(0.84)$ & 6.14 & 18.41 & 18.15 & 1.18 & $-1.70(0.17)$ & 7.42 \\
\hline CESM1-WACCM & 14.33 & 12.57 & 0.39 & $-6.45(0.54)$ & 2.95 & 11.55 & 13.15 & 0.66 & $-0.91(0.09)$ & 1.80 \\
\hline CMCC-CESM & 11.84 & 19.43 & 0.99 & $2.91(1.39)$ & 2.01 & 6.70 & 11.18 & 0.71 & $0.26(0.10)$ & 4.91 \\
\hline CMCC-CM & 11.81 & 16.84 & 0.67 & $-2.49(0.94)$ & 0.90 & 6.82 & 10.14 & 0.48 & $-0.05(0.07)$ & 4.97 \\
\hline CMCC-CMS & 11.74 & 19.33 & 0.87 & $-1.52(1.23)$ & 1.83 & 6.31 & 10.70 & 0.59 & $-0.12(0.08)$ & 5.34 \\
\hline CNRM-CM5 & 7.78 & 16.98 & 0.77 & $-2.59(1.09)$ & 4.53 & 3.01 & 7.81 & 0.42 & $-0.10(0.06)$ & 8.79 \\
\hline CNRM-CM5-2 & 9.28 & 14.08 & 1.08 & $4.29(1.51)$ & 3.16 & 4.93 & 9.78 & 1.02 & $0.38(0.14)$ & 6.77 \\
\hline CSIRO-Mk3.6 & 15.92 & 12.11 & 0.67 & $-1.64(0.95)$ & 4.89 & 12.13 & 13.28 & 0.65 & $-0.29(0.09)$ & 2.62 \\
\hline EC-EARTH & 10.66 & 17.18 & 0.66 & $-7.94(0.92)$ & 1.72 & 6.09 & 9.44 & 0.58 & $-0.66(0.08)$ & 5.75 \\
\hline FGOALS-g2 & 17.10 & 17.29 & 0.48 & $-1.47(0.67)$ & 5.28 & 15.65 & 13.89 & 0.74 & $-0.14(0.10)$ & 4.88 \\
\hline FIO-ESM & 17.19 & 12.21 & 0.49 & $-8.53(0.68)$ & 5.61 & 21.23 & 13.98 & 1.16 & $-1.57(0.16)$ & 10.31 \\
\hline GFDL-CM2p1 & 8.00 & 15.38 & 0.81 & $-6.33(1.14)$ & 4.01 & 2.45 & 5.55 & 0.30 & $-0.19(0.04)$ & 9.57 \\
\hline GFDL-CM3 & 6.25 & 12.06 & 0.73 & $-6.82(1.02)$ & 5.82 & 1.92 & 4.16 & 0.37 & $-0.30(0.05)$ & 10.29 \\
\hline GFDL-ESM2G & 8.11 & 14.34 & 0.63 & $-4.45(0.88)$ & 3.90 & 2.71 & 5.81 & 0.41 & $-0.24(0.06)$ & 9.31 \\
\hline GFDL-ESM2M & 6.39 & 12.23 & 0.41 & $-1.61(0.58)$ & 5.65 & 1.81 & 4.20 & 0.16 & $-0.09(0.02)$ & 10.36 \\
\hline GISS-E2-H & 6.21 & 10.62 & 0.38 & $-1.89(0.53)$ & 6.03 & 3.24 & 7.19 & 0.27 & $-0.24(0.04)$ & 8.65 \\
\hline GISS-E2-H-CC & 12.18 & 19.07 & 0.75 & $-5.75(1.05)$ & 1.52 & 6.70 & 14.16 & 0.51 & $-0.54(0.07)$ & 4.57 \\
\hline GISS-E2-R & 7.74 & 14.31 & 1.01 & $-3.39(1.42)$ & 4.31 & 3.06 & 6.17 & 0.47 & $-0.16(0.07)$ & 8.92 \\
\hline GISS-E2-R-CC & 8.12 & 14.55 & 0.66 & $0.82(0.92)$ & 3.93 & 3.12 & 6.24 & 0.35 & $0.00(0.05)$ & 8.86 \\
\hline HadCM3 & 14.26 & 19.95 & 0.78 & $-2.74(1.10)$ & 3.28 & 14.70 & 21.87 & 0.83 & $-0.49(0.12)$ & 4.13 \\
\hline HadGEM2-AO & 9.11 & 14.29 & 0.59 & $-5.31(0.83)$ & 3.20 & 5.58 & 9.70 & 0.49 & $-0.42(0.07)$ & 6.26 \\
\hline HadGEM2-CC & 9.12 & 14.29 & 0.72 & $-0.85(1.02)$ & 3.25 & 5.50 & 9.68 & 0.61 & $-0.05(0.09)$ & 6.34 \\
\hline HadGEM2-ES & 9.82 & 15.02 & 0.70 & $-3.25(0.98)$ & 2.60 & 6.16 & 10.33 & 0.61 & $-0.41(0.09)$ & 5.66 \\
\hline INMCM4 & 6.25 & 10.91 & 0.48 & $-4.00(0.68)$ & 6.04 & 2.81 & 6.12 & 0.38 & $-0.28(0.05)$ & 9.21 \\
\hline IPSL-CM5A-LR & 9.66 & 19.06 & 0.84 & $-5.03(1.17)$ & 3.43 & 4.13 & 8.66 & 0.53 & $-0.26(0.07)$ & 7.70 \\
\hline IPSL-CM5A-MR & 8.08 & 17.30 & 0.74 & $1.69(1.04)$ & 4.56 & 2.80 & 6.50 & 0.35 & $0.01(0.05)$ & 9.21 \\
\hline IPSL-CM5B-LR & 3.34 & 8.09 & 0.42 & $0.59(0.59)$ & 9.09 & 1.22 & 3.32 & 0.20 & $0.04(0.03)$ & 11.10 \\
\hline MIROC4h & 10.90 & 17.53 & 0.61 & $-7.96(0.86)$ & 1.33 & 5.35 & 9.74 & 0.41 & $-0.51(0.06)$ & 6.28 \\
\hline MIROC5 & 3.23 & 6.62 & 0.29 & $-1.03(0.41)$ & 9.29 & 1.40 & 3.15 & 0.16 & $-0.07(0.02)$ & 10.93 \\
\hline MIROC-ESM & 12.65 & 19.12 & 0.64 & $-5.83(0.91)$ & 1.47 & 7.23 & 10.72 & 0.47 & $-0.48(0.07)$ & 4.46 \\
\hline MIROC-ESM-CHEM & 13.38 & 19.80 & 0.53 & $-2.15(0.74)$ & 2.07 & 8.08 & 11.59 & 0.49 & $-0.21(0.07)$ & 3.61 \\
\hline MPI-ESM-LR & 7.70 & 15.08 & 0.73 & $-2.95(1.03)$ & 4.50 & 3.41 & 6.35 & 0.38 & $-0.19(0.05)$ & 8.64 \\
\hline MPI-ESM-MR & 7.90 & 15.62 & 0.84 & $4.41(1.17)$ & 4.28 & 3.54 & 7.06 & 0.48 & $0.24(0.07)$ & 8.39 \\
\hline MPI-ESM-P & 7.91 & 15.69 & 0.75 & $-0.25(1.06)$ & 4.34 & 3.48 & 6.48 & 0.45 & $0.05(0.06)$ & 8.56 \\
\hline MRI-CGCM3 & 13.43 & 15.99 & 0.66 & $1.52(0.93)$ & 1.67 & 10.72 & 13.05 & 0.63 & $0.22(0.09)$ & 2.04 \\
\hline MRI-ESM1 & 13.24 & 16.32 & 0.75 & $-0.62(1.05)$ & 1.53 & 10.14 & 13.00 & 0.58 & $-0.03(0.08)$ & 2.25 \\
\hline NorESM1-M & 13.08 & 14.19 & 0.57 & $-0.71(0.80)$ & 1.24 & 13.88 & 12.41 & 1.17 & $-0.07(0.16)$ & 3.66 \\
\hline NorESM1-ME & 16.98 & 14.19 & 0.60 & $-3.77(0.84)$ & 5.24 & 17.57 & 16.82 & 1.40 & $-0.74(0.20)$ & 6.59 \\
\hline
\end{tabular}



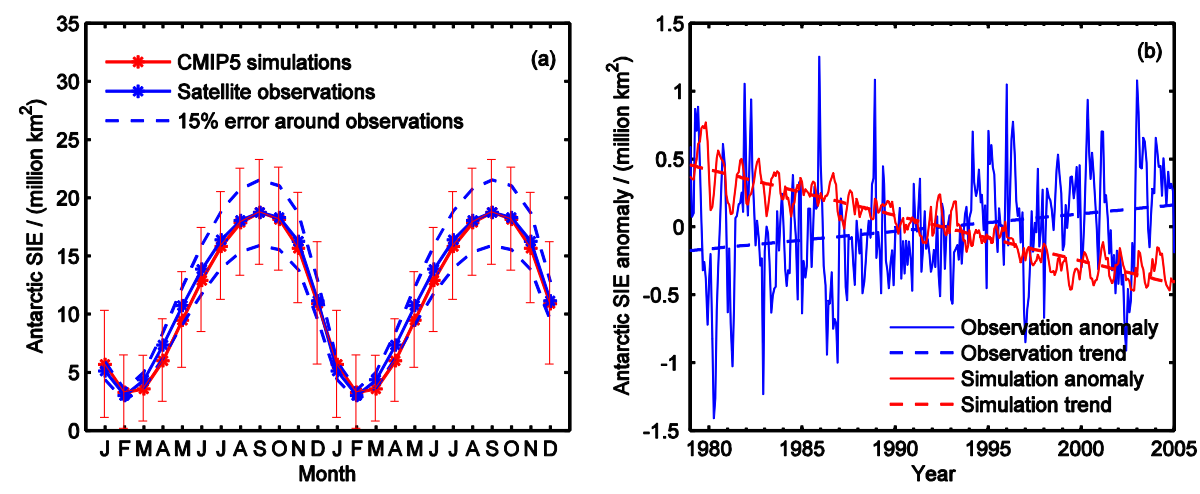

Figure 1. Climatology (a), anomaly and linear trend (b) of satellite-observed and CMIP5-simulated Antarctic sea ice extent during 19792005. Two annual cycles are plotted in (a). The error bar is the range of 1 standard deviation.

variability), SIE linear trend and CMIP5-simulated SIE root mean square (RMS) error are shown in Tables 1 and 2. The same metrics for SIV are also shown in Tables 1 and 2. Each CMIP5 model-simulated SIC and sea ice thickness are given in the Supplement. Detailed analyses for Antarctic and Arctic are as follows.

\subsection{Assessment of Antarctic sea ice simulations}

CMIP5 multi-model ensemble mean (MME) Antarctic climatological SIE compares well with the satellite-observed SIE, but the inter-model spread is large (Fig. 1a and Table 1). Satellite observations show that the Antarctic SIE has the minimum value of 3.0 million $\mathrm{km}^{2}$ in February and the maximum value of 18.7 million $\mathrm{km}^{2}$ in September; the annual mean SIE is 11.94 million $\mathrm{km}^{2}$. CMIP5 MME SIE has the minimum and maximum values of 3.3 and 18.7 million $\mathrm{km}^{2}$, and annual mean SIE of 11.50 million $\mathrm{km}^{2}$, respectively. The seasonal cycle of observed SIE is well represented by the MME SIE of the 49 CMIP5 coupled models. Satelliteobserved monthly SIE amplitude is 15.70 million $\mathrm{km}^{2}$, and CMIP5 MME value is 15.46 million $\mathrm{km}^{2}$. The simulated SIE errors are very small for each month. The simulated SIE errors are smaller than $15 \%$ of the observations, except for March and April SIE values, which are a little less than $85 \%$ of the observations. One standard deviation of CMIP5 simulations, which is greater than $15 \%$ of the observations (Fig. 1a), shows that CMIP5 coupled models have a large spread each month in terms of Antarctic SIE. Table 1 also shows that CMIP5 models have a large spread. BNU-ESM has the largest annual mean and amplitude of SIE with the values of 20.60 and 23.46 million $\mathrm{km}^{2}$, and MIROC5 has the smallest annual mean and amplitude of SIE with the values of 3.23 and 6.62 million $\mathrm{km}^{2}$ (highlighted in Table 1 with bold font), respectively. BNU-ESM-simulated February SIE is even larger than MIROC5-simulated September SIE. Large SIE spread and small MME SIE errors indicate that we should use as many models as we can when using CMIP5 outputs.
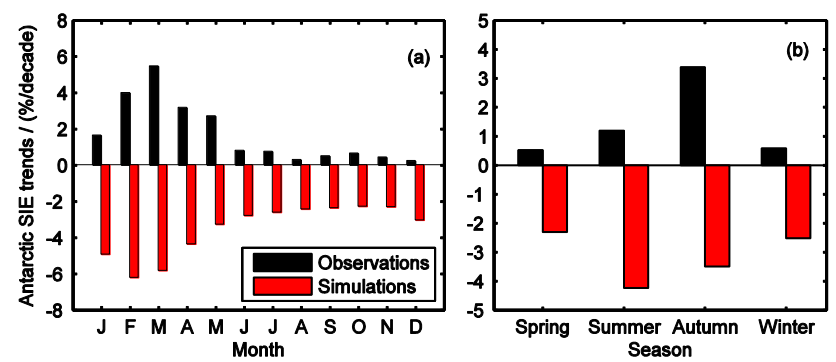

Figure 2. Monthly (a) and seasonal (b) linear trends of satelliteobserved and CMIP5-simulated Antarctic sea ice extent during 1979-2005.

CMIP5 model-simulated and satellite-observed SICs in February and September during 1979-2005 are shown in Figs. S3 and S4. In February most models have an overly small SIC compared with satellite observations, especially in the Bellingshausen Sea and the Amundsen Sea. More than half of CMIP5 models have no sea ice in the Bellingshausen Sea or in the Amundsen Sea. CNRMCM5, GFDL-CM2p1, GFDL-CM3, GFDL-ESM2G, GFDLESM2M, IPSL-CM5B-LR and MIROC5 almost have no sea ice in February in the Antarctic. But ACCESS1.3, BNU-ESM, CCSM4, CESM1-BGC, CESM1-FASTCHEM, CSIRO-Mk3.6, FGOALS-g2, FIO-ESM and NorESM1-ME have more sea ice than satellite observations. Although CMIP5 simulated MME SIE fits the observations well, the MME spatial pattern of SIC does not fit the observations so well. MME SICs in the Weddell Sea, the Bellingshausen Sea and the Amundsen Sea are smaller than the observations. In September, most CMIP5 models have better performance than that in February, and MME SIC also has a better spatial pattern.

Figures $1 \mathrm{~b}$ and 2 show that linear trends of CMIP5 MME Antarctic SIE do not agree with the satellite observations. Many studies showed that Antarctic SIE has an increasing trend since the end of 1970s (Cavalieri et 
Table 2. Arctic sea ice metrics in CMIP5 models, satellite observations and PIOMAS data set. Column (a) is mean annual SIE in million km ${ }^{2}$. Column (b) is monthly SIE amplitude in million $\mathrm{km}^{2}$. Column (c) is standard deviation of detrended monthly SIE anomaly in million $\mathrm{km}^{2}$. Column (d) is linear trend in monthly SIE in $10^{5} \mathrm{~km}^{2}$ decade ${ }^{-1}$, and the value in parentheses is $95 \%$ confidence level. Column (e) is monthly SIE root mean square error in million $\mathrm{km}^{2}$. Column (f) is mean annual SIV in $10^{3} \mathrm{~km}^{3}$. Column (g) is monthly SIV amplitude in $10^{3} \mathrm{~km}^{3}$. Column (h) is standard deviation of detrended monthly SIV anomaly in $10^{3} \mathrm{~km}^{3}$. Column (i) is linear trend in monthly SIV in $10^{3} \mathrm{~km}^{3}$ decade $^{-1}$, and the value in parentheses is $95 \%$ confidence level. Column (j) is monthly SIV root mean square error in $10^{3} \mathrm{~km}^{3}$. The models with bold metric number have special performances, and details can be found in the text.

\begin{tabular}{|c|c|c|c|c|c|c|c|c|c|c|}
\hline $\begin{array}{l}\text { Data sources or CMIP5 } \\
\text { models }\end{array}$ & (a) & (b) & (c) & (d) & (e) & (f) & $(\mathrm{g})$ & (h) & (i) & (j) \\
\hline Observations or PIOMAS & 12.02 & 8.80 & 0.29 & $-4.35(0.41)$ & - & 21.85 & 16.17 & 1.02 & $-2.14(0.14)$ & - \\
\hline Multi-model ensemble mean (MME) & 12.81 & 10.40 & 0.13 & $-3.71(0.19)$ & 1.07 & 18.45 & 17.50 & 0.35 & $-1.45(0.05)$ & 3.57 \\
\hline ACCESS 1.0 & 12.13 & 10.33 & 0.41 & $-5.51(0.57)$ & 0.94 & 15.41 & 18.74 & 1.05 & $-1.58(0.15)$ & 6.60 \\
\hline ACCESS1.3 & 11.79 & 9.47 & 0.43 & $-0.78(0.60)$ & 0.73 & 18.81 & 17.02 & 1.02 & $-1.05(0.14)$ & 3.23 \\
\hline BCC-CSM1.1 & 14.86 & 15.39 & 0.69 & $-8.79(0.97)$ & 3.70 & 14.29 & 22.70 & 1.00 & $-2.01(0.14)$ & 8.02 \\
\hline BCC-CSM1-1-M & 13.19 & 15.96 & 0.65 & $-5.19(0.92)$ & 2.87 & 11.04 & 20.69 & 0.87 & $-0.74(0.12)$ & 11.02 \\
\hline BNU-ESM & 14.72 & 12.61 & 0.50 & $-4.41(0.70)$ & 3.19 & 23.03 & 19.79 & 1.23 & $-4.37(0.17)$ & 1.83 \\
\hline CanCM4 & 12.79 & 14.77 & 0.52 & $-4.97(0.73)$ & 2.49 & 11.41 & 15.35 & 0.97 & $-0.38(0.14)$ & 10.47 \\
\hline CanESM2 & 12.01 & 13.76 & 0.49 & $-6.80(0.69)$ & 1.91 & 9.97 & 14.21 & 0.63 & $-1.18(0.09)$ & 11.92 \\
\hline CCSM4 & 12.33 & 8.56 & 0.44 & $-1.34(0.62)$ & 0.42 & 20.27 & 16.16 & 1.51 & $-1.54(0.21)$ & 1.82 \\
\hline CESM1-BGC & 12.10 & 7.96 & 0.41 & $-2.85(0.58)$ & 0.35 & 20.30 & 15.52 & 1.51 & $-2.63(0.21)$ & 1.86 \\
\hline CESM1-CAM5 & 12.33 & 8.35 & 0.38 & $-1.87(0.53)$ & 0.52 & 22.73 & 16.01 & 1.96 & $-1.22(0.28)$ & 1.35 \\
\hline CESM1-CAM5-1-FV2 & 12.52 & 8.68 & 0.42 & $-5.07(0.59)$ & 0.64 & 23.17 & 16.01 & 1.87 & $-3.63(0.26)$ & 1.49 \\
\hline CESM1-FASTCHEM & 12.02 & 8.86 & 0.39 & $-3.70(0.55)$ & 0.25 & 18.27 & 15.86 & 1.37 & $-1.98(0.19)$ & 3.69 \\
\hline CESM1-WACCM & 13.44 & 8.10 & 0.36 & $-2.88(0.51)$ & 1.51 & 27.32 & 9.47 & 2.07 & $0.09(0.29)$ & 6.27 \\
\hline CMCC-CESM & 13.97 & 9.33 & 0.36 & $-2.63(0.51)$ & 2.12 & 28.75 & 11.93 & 1.38 & $-1.44(0.19)$ & 7.11 \\
\hline CMCC-CM & 13.99 & 7.35 & 0.30 & $-5.09(0.43)$ & 2.06 & 33.01 & 9.87 & 1.73 & $-2.40(0.24)$ & 11.52 \\
\hline CMCC-CMS & 12.64 & 7.92 & 0.34 & $-2.87(0.48)$ & 0.82 & 28.29 & 9.73 & 1.29 & $-1.18(0.18)$ & 6.89 \\
\hline CNRM-CM5 & 12.41 & 11.41 & 0.46 & $-7.58(0.65)$ & 1.11 & 14.44 & 20.22 & 0.99 & $-1.76(0.14)$ & 7.60 \\
\hline CNRM-CM5-2 & 14.20 & 10.65 & 0.45 & $-2.32(0.63)$ & 2.40 & 20.11 & 21.83 & 1.29 & $-0.96(0.18)$ & 2.76 \\
\hline CSIRO-Mk3.6 & 16.13 & 7.57 & 0.30 & $-5.33(0.42)$ & 4.20 & 25.94 & 12.16 & 0.81 & $-2.32(0.11)$ & 4.30 \\
\hline EC-EARTH & 12.45 & 8.04 & 0.35 & $-3.84(0.49)$ & 0.57 & 24.01 & 12.44 & 1.90 & $-0.59(0.27)$ & 2.86 \\
\hline FGOALS-g2 & 11.68 & 3.35 & 0.13 & $-1.44(0.18)$ & 1.86 & - & - & - & - & - \\
\hline FIO-ESM & 12.46 & 10.27 & 0.40 & $-2.23(0.57)$ & 1.00 & 18.94 & 18.96 & 1.86 & $-1.69(0.26)$ & 3.15 \\
\hline GFDL-CM2p1 & 12.58 & 12.85 & 0.54 & $-3.76(0.75)$ & 1.68 & 11.11 & 18.13 & 0.87 & $-1.01(0.12)$ & 10.80 \\
\hline GFDL-CM3 & 12.22 & 8.71 & 0.33 & $-2.89(0.46)$ & 0.41 & 15.25 & 15.47 & 1.31 & $-1.18(0.18)$ & 6.61 \\
\hline GFDL-ESM2G & 15.72 & 13.72 & 0.48 & $-7.05(0.68)$ & 4.24 & 16.91 & 19.33 & 1.24 & $-1.77(0.17)$ & 5.17 \\
\hline GFDL-ESM2M & 12.46 & 11.06 & 0.53 & $-0.31(0.74)$ & 0.98 & 12.13 & 16.11 & 1.02 & $-0.56(0.14)$ & 9.75 \\
\hline GISS-E2-H & 12.96 & 14.87 & 0.54 & $-5.07(0.75)$ & 2.47 & 13.61 & 25.67 & 0.76 & $-0.91(0.11)$ & 9.10 \\
\hline GISS-E2-H-CC & 13.94 & 14.24 & 0.60 & $-5.91(0.84)$ & 2.80 & 14.94 & 27.49 & 0.80 & $-1.29(0.11)$ & 8.23 \\
\hline GISS-E2-R & 13.65 & 15.17 & 0.49 & $-6.31(0.69)$ & 2.89 & 15.50 & 29.32 & 0.75 & $-1.28(0.11)$ & 8.17 \\
\hline GISS-E2-R-CC & 15.13 & 16.73 & 0.48 & $-5.65(0.67)$ & 4.28 & 17.16 & 31.86 & 0.76 & $-1.08(0.11)$ & 7.64 \\
\hline HadCM3 & 13.94 & 13.59 & 0.56 & $-4.74(0.78)$ & 2.78 & 21.07 & 26.96 & 0.87 & $-2.25(0.12)$ & 4.46 \\
\hline HadGEM2-AO & 11.38 & 10.75 & 0.40 & $-3.81(0.56)$ & 1.15 & 16.58 & 20.16 & 0.84 & $-0.98(0.12)$ & 5.53 \\
\hline HadGEM2-CC & 13.20 & 10.68 & 0.45 & $-3.10(0.63)$ & 1.45 & 21.56 & 21.55 & 0.96 & $-2.47(0.13)$ & 2.22 \\
\hline HadGEM2-ES & 12.34 & 11.21 & 0.43 & $-6.03(0.60)$ & 1.14 & 18.85 & 21.13 & 1.00 & $-1.69(0.14)$ & 3.64 \\
\hline INMCM4 & 12.92 & 12.02 & 0.42 & $-0.21(0.59)$ & 1.61 & 15.20 & 22.08 & 0.96 & $-0.21(0.13)$ & 7.07 \\
\hline IPSL-CM5A-LR & 12.72 & 10.07 & 0.44 & $-3.03(0.62)$ & 1.14 & 21.87 & 16.41 & 1.48 & $-0.96(0.21)$ & 1.66 \\
\hline IPSL-CM5A-MR & 11.06 & 9.55 & 0.35 & $-2.85(0.49)$ & 1.25 & 14.83 & 16.32 & 0.92 & $-1.69(0.13)$ & 7.17 \\
\hline IPSL-CM5B-LR & 14.06 & 8.28 & 0.40 & $-0.77(0.56)$ & 2.08 & 27.28 & 13.11 & 2.91 & $-1.37(0.41)$ & 6.25 \\
\hline MIROC4h & 10.66 & 9.65 & 0.40 & $-3.11(0.56)$ & 1.47 & 10.86 & 16.48 & 0.82 & $-1.00(0.12)$ & 11.02 \\
\hline MIROC5 & 12.12 & 6.63 & 0.29 & $-6.78(0.40)$ & 0.65 & 25.31 & 14.88 & 1.09 & $-3.68(0.15)$ & 3.81 \\
\hline MIROC-ESM & 10.40 & 8.05 & 0.34 & $-1.91(0.47)$ & 1.69 & 11.09 & 14.36 & 0.62 & $-1.04(0.09)$ & 10.79 \\
\hline MIROC-ESM-CHEM & 10.83 & 7.89 & 0.46 & $-4.24(0.65)$ & 1.30 & 12.59 & 14.73 & 1.39 & $-1.69(0.20)$ & 9.29 \\
\hline MPI-ESM-LR & 11.10 & 7.95 & 0.40 & $-2.48(0.56)$ & 1.01 & 15.07 & 16.87 & 0.85 & $-1.23(0.12)$ & 6.85 \\
\hline MPI-ESM-MR & 11.07 & 8.00 & 0.40 & $-4.94(0.56)$ & 1.02 & 15.20 & 17.30 & 0.90 & $-1.75(0.13)$ & 6.74 \\
\hline MPI-ESM-P & 10.94 & 8.27 & 0.34 & $-1.83(0.48)$ & 1.13 & 13.45 & 17.05 & 1.13 & $-0.80(0.16)$ & 8.46 \\
\hline MRI-CGCM3 & 15.01 & 15.27 & 0.47 & $-1.44(0.66)$ & 3.97 & 15.70 & 19.40 & 1.48 & $-0.55(0.21)$ & 6.33 \\
\hline MRI-ESM1 & 14.65 & 14.67 & 0.61 & $-4.07(0.86)$ & 3.52 & 15.21 & 18.89 & 1.74 & $-1.56(0.24)$ & 6.76 \\
\hline NorESM1-M & 12.01 & 5.96 & 0.25 & $-1.98(0.36)$ & 0.90 & 23.77 & 11.23 & 1.57 & $-0.68(0.22)$ & 3.11 \\
\hline NorESM1-ME & 12.47 & 5.99 & 0.31 & $-0.21(0.43)$ & 0.97 & 23.97 & 9.71 & 2.14 & $-0.46(0.30)$ & 3.69 \\
\hline
\end{tabular}



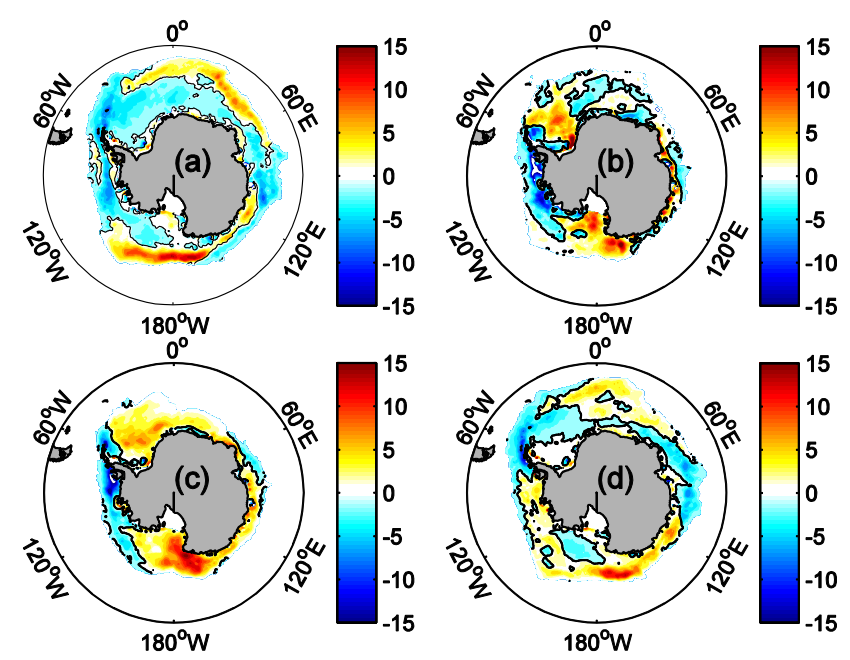

Figure 3. Linear trends (unit: \% per decade) of satellite-observed Antarctic sea ice concentration during 1979 to 2005. (a) Spring, (b) summer, (c) autumn, and (d) winter.

al., 1997, 2003; Zwally et al., 2002; Turner et al., 2009). Satellite-observed Antarctic SIE has a small increasing linear trend with the rate of $1.29( \pm 0.57) \times 10^{5} \mathrm{~km}^{2} \mathrm{decade}^{-1}$ during 1979-2005, while CMIP5-simulated linear trend is $-3.36( \pm 0.15) \times 10^{5} \mathrm{~km}^{2} \mathrm{decade}^{-1}$ (Fig. 1b). Only 8 out of 49 CMIP5 models have increasing linear trends as the observations (highlighted in Table 1 with bold font). They are BCC-CSM1.1, CMCC-CESM, CNRM-CM5-2, GISS-E2-RCC, IPSL-CM5A-MR, IPSL-CM5B-LR, MPI-ESM-MR and MRI-CGCM3. This supports the conclusion by Polvani et al. (2013) that it is difficult to attribute the observed Antarctic SIE trends to anthropogenic forcing. From Table 1 we can see that several models (highlighted in Table 1 with bold font) such as BCC-CSM1.1, BCC-CSM1-1-M, CanESM2, CMCC-CESM, CNRM-CM5-2 and GISS-E2-R have large internal variabilities, and these models always have large linear trends. This mean that the satellite-observed positive SIE trend may represent natural variation along with external forcing (Mahlstein et al., 2013). Figure 2 shows that the monthly and seasonal trends of CMIP5-simulated Antarctic SIE also do not agree with the observations. Observed Antarctic SIE shows increasing trends in each month and each season, and the largest trend is in March and the autumn season. CMIP5 MME SIE, however, has decreasing trends in each month and each season, and the largest trend is in February and the summer season.

The trends of observed Antarctic SIC have large spatial differences (Fig. 3), but the simulated Antarctic SIC trends are almost decreasing everywhere (Fig. 4). Figure 3 shows that decreasing SIC is mainly in the Antarctic Peninsula, which is one of the three high-latitude areas showing rapid regional warming over the last 50 years (Vaughan et al., 2003). SIC also decreases in the Bellingshausen Sea and the Amundsen Sea in summer and autumn. The increasing SIC
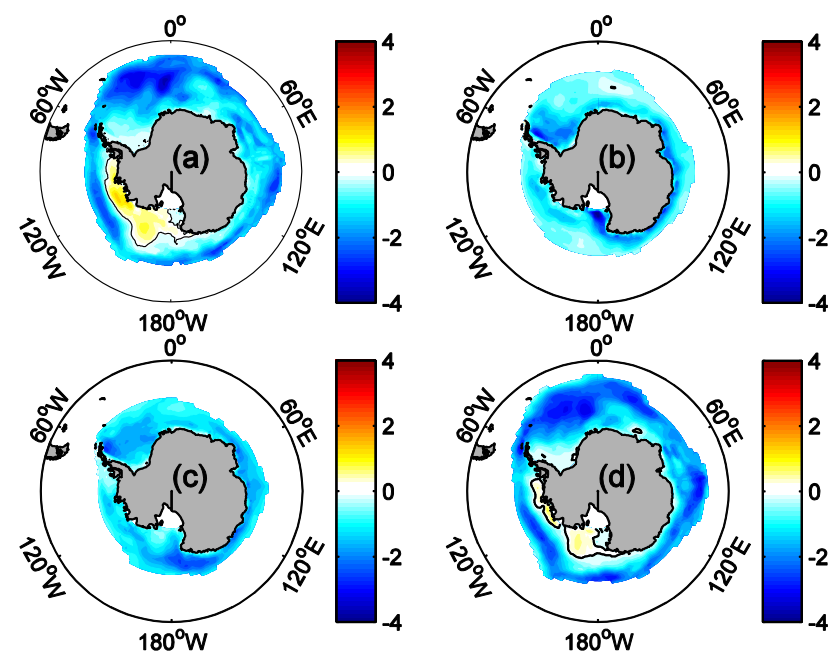

Figure 4. Linear trends (units: \% per decade) of CMIP5-simulated Antarctic sea ice concentration during 1979-2005. (a) Spring, (b) summer, (c) autumn, and (d) winter.

is mainly in the Ross Sea all year round and in the Weddell Sea in summer and autumn. Figure 4 clearly shows that CMIP5 MME SIC has decreasing trend everywhere except in the coast of the Amundsen Sea and in part of the Ross Sea in spring and winter.

SIV depends on both sea ice coverage and sea ice thickness. SIV is more directly tied to climate forcing than SIE. So, SIV is an important climate indicator in climate study. The observed sea ice thickness records are mainly from submarine, aircraft and satellite. But the observations are not continuous spatially or temporally over a long period (Stroeve et al., 2014). For the Antarctic, the observed sea ice thickness data are quite limited. A climatological $2.5^{\circ} \times 5.0^{\circ}$ gridded Antarctic sea ice thickness map was provided until 2008 (Worby et al., 2008). Recently, there have been several studies using satellite observations of sea ice thickness (Kurtz and Markus, 2012; Xie et al., 2013). These observations provide modelers with useful validation of their models. However, these data are not easily used to long-term simulation validations by now, because they are not long enough. Here, we use GIOMAS data, which are from a global iceocean model (Zhang and Rothrock, 2003) with data assimilation capability. What we should keep in mind is that GIOMAS sea ice thickness is not from observations and may also have large degrees of uncertainty. CMIP5-simulated and GIOMAS Antarctic sea ice thicknesses during 1979-2005 are shown in Fig. S5. GIOMAS outputs show that thick sea ice is mainly in the coasts of the Weddell Sea, the Bellingshausen Sea and the Amundsen Sea. CMIP5 MME sea ice thickness can reproduce similar spatial patterns, but most of CMIP5 MME sea ice thickness is thinner than GIOMAS sea ice thickness. The spatial pattern for each CMIP5 model has a large difference. BCC-CSM1.1, CESM1-CAM5-1-FV2, 

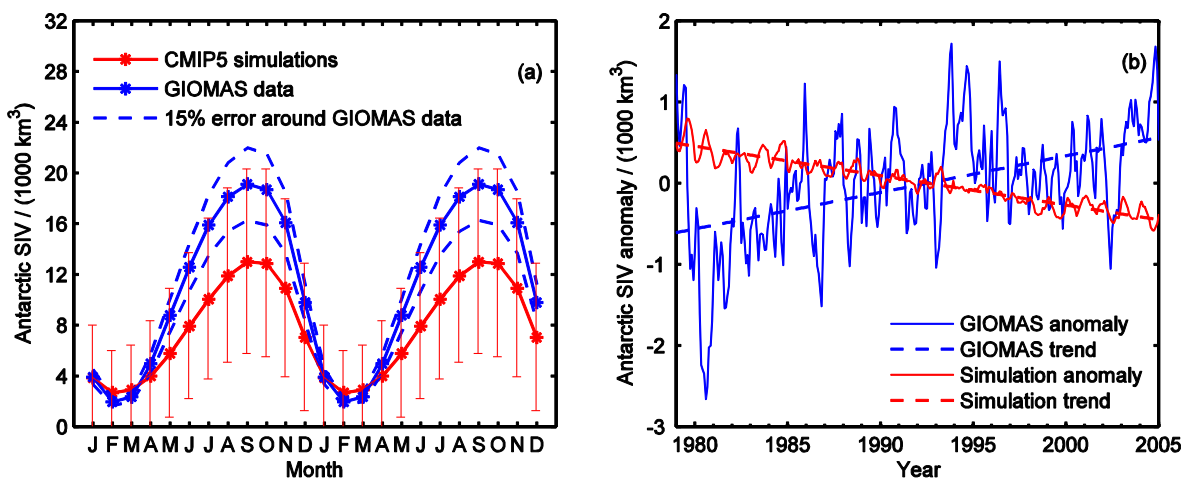

Figure 5. Climatology (a), anomaly and linear trend (b) of GIOMAS and CMIP5-simulated Antarctic sea ice volume during 1979-2005. Two annual cycles are plotted in (a). The error bar is the range of 1 standard deviation.

CMCC-CM, and CMCC-CMS fit GIOMAS sea ice thickness well. Several CMIP5 models such as CCSM4, CESM1BGC, CESM1-FASTCHEM, FGOALS-g2 and FIO-ESM have overly thick sea ice near the coasts of Antarctica.

CMIP5 SIV simulations have more problems than the SIE simulations. The main problems of CMIP5 Antarctic SIV simulations include overly big SIV in summer, overly small SIV in winter, overly large model spread, and an incorrect linear trend compared with the GIOMAS data (Fig. 5). The annual mean SIV from GIOMAS is $11.02 \times 10^{3} \mathrm{~km}^{3}$, but CMIP5 MME SIV is only $7.73 \times 10^{3} \mathrm{~km}^{3}$ (Table 1 ). In February, Antarctic SIV from GIOMAS is $1.9 \times 10^{3} \mathrm{~km}^{3}$, while the CMIP5 MME is $2.7 \times 10^{3} \mathrm{~km}^{3}$. In September, GIOMAS SIV is $19.1 \times 10^{3} \mathrm{~km}^{3}$, while CMIP5 MME is only $13.0 \times 10^{3} \mathrm{~km}^{3}$, almost $32 \%$ less than the GIOMAS. We can also see from Figure 5a that the model spread of Antarctic SIV in CMIP5 is very large. One standard deviation is greater than $15 \%$ of the GIOMAS data in every month. We checked the correlation between SIE RMS error and SIV RMS error, and we can find that the models with small SIE RMS errors always have small SIV RMS errors (Table 1). It means that for the Antarctic models with a more realistic SIE mean state may result in a convergence of estimates of SIV. Figure $5 \mathrm{~b}$ shows that GIOMAS SIV has an increasing trend of 0.45 $( \pm 0.09) \times 10^{3} \mathrm{~km}^{3} \mathrm{decade}^{-1}$, while CMIP5 MME SIV has a decreasing trend of $-0.36( \pm 0.01) \times 10^{3} \mathrm{~km}^{3}$ decade $^{-1}$. If we check each CMIP5 model separately, we will also find that only 8 out of the 49 CMIP5 models have increasing SIV trend that is consistent with the GIOMAS. They are BCC-CSM1.1, CMCC-CESM, CNRM-CM5-2, IPSLCM5A-MR, IPSL-CM5B-LR, MPI-ESM-MR, MPI-ESM-P and MRI-CGCM3 (highlighted in Table 1 with bold font).

\subsection{Assessment of Arctic sea ice simulations}

CMIP5 shows a quite good annual cycle of Arctic SIE, but the model error in winter is larger than that in summer and model spread is large (Fig. 6a). Arctic SIE reaches the maximum value of 15.7 million $\mathrm{km}^{2}$ in March, and it reaches the minimum value of 6.9 million $\mathrm{km}^{2}$ in September; the annual mean value is 12.02 million $\mathrm{km}^{2}$. The MME climatological SIE compares well with the satellite-observed SIE. CMIP5 MME SIE reaches the maximum value of 17.2 million $\mathrm{km}^{2}$, and reaches the minimum value of 6.8 million $\mathrm{km}^{2}$, and the annual mean value is 12.81 million $\mathrm{km}^{2}$. The modeled error is less than $15 \%$ of the observations in every month. CMIP5 MME SIE is bigger than the satellite observation in spring, and the modeled error is quite small at other times. The model spread is large, with 1 standard deviation greater than $15 \%$ of the observed SIE in every month (Fig. 6a). CSIRO-MK3.6, GFDL-ESM2G, GISS-E2-R-CC and MRICGCM3 have large annual mean SIE with the values larger than 15 million $\mathrm{km}^{2}$ (highlighted in Table 2 with bold font). CSIRO-MK3.6 has more sea ice in the Barents Sea in summer (Fig. S6). GFDL-ESM2G, GISS-E2-R-CC and MRICGCM3 have more sea ice in winter (Fig. S7). MIROC4h, MIROC-ESM, MIROC-ESM-CHEM and MPI-ESM-P have small annual mean SIE with the values less than 11 million square kilometers (highlighted in Table 1 with bold font). Arctic SIE amplitudes from CMIP5 models also have a large spread. GISS-E2-R-CC has the largest amplitude with the value of 16.73 million $\mathrm{km}^{2}$, and FGOAL-g2 has the smallest amplitude with the value of only 3.35 million $\mathrm{km}^{2}$ (highlighted in Table 2 with bold font). Compared with the Antarctic variability, CMIP5-simulated Arctic SIE variability has a small spread (column c in Table 2).

CMIP5 MME SIE shows a decreasing trend that is consistent with the satellite observation, though the decreasing rate is a little smaller than that of the observation (Figs. 6b and 7). The satellite-observed SIE linear trend over the period of $1979-2005$ is $-4.35( \pm 0.41) \times 10^{5} \mathrm{~km}^{2} \mathrm{decade}^{-1}$, while CMIP5 MME SIE linear trend is only -3.71 $( \pm 0.19) \times 10^{5} \mathrm{~km}^{2} \mathrm{decade}^{-1}$. BCC-CSM1.1 has the largest trend of $-8.79( \pm 0.97) \times 10^{5} \mathrm{~km}^{2} \mathrm{decade}^{-1}$. A total of 31 out of the 49 CMIP5 models have smaller decreasing rate than the observation, and NorESM1-ME has the smallest trend of $-0.21( \pm 0.43) \times 10^{5} \mathrm{~km}^{2}$ decade $^{-1}$. Both observed 

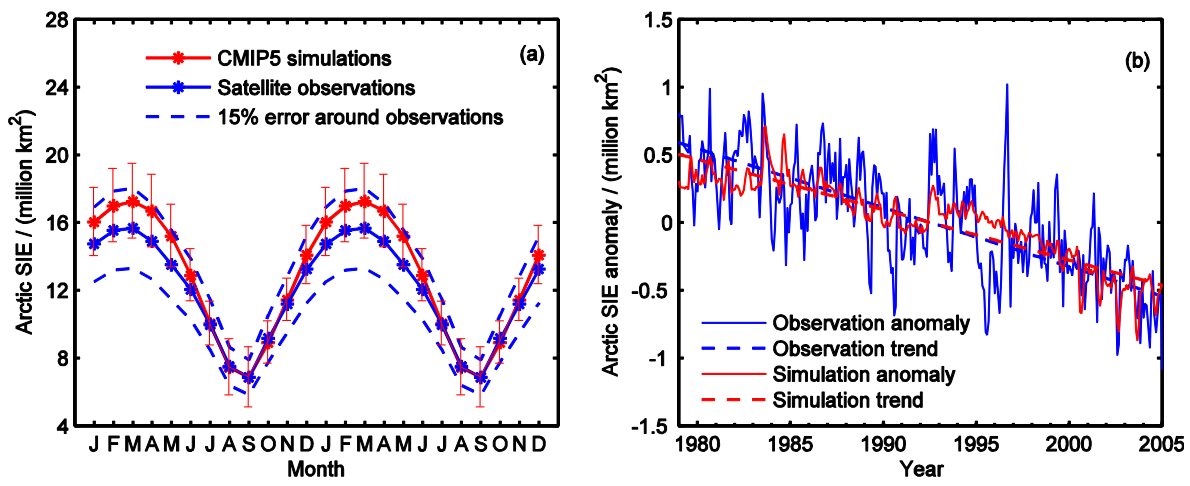

Figure 6. Climatology (a), anomaly and linear trend (b) of satellite-observed and CMIP5-simulated Arctic sea ice extent during 1979-2005. Two annual cycles are plotted in (a). The error bar is the range of 1 standard deviation.

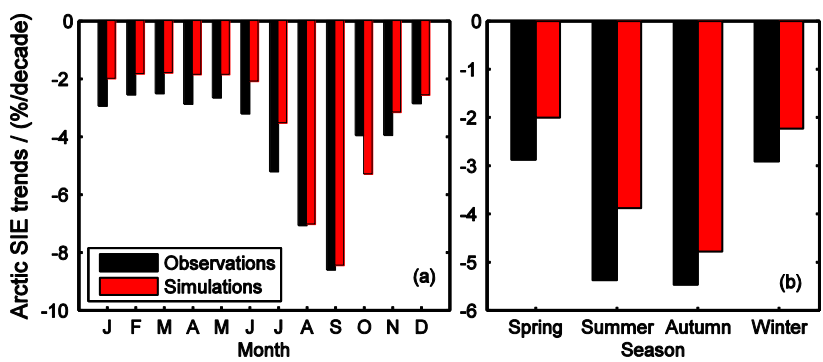

Figure 7. Monthly (a) and seasonal (b) linear trends of satelliteobserved and CMIP5-simulated Arctic sea ice extent during 19792005.
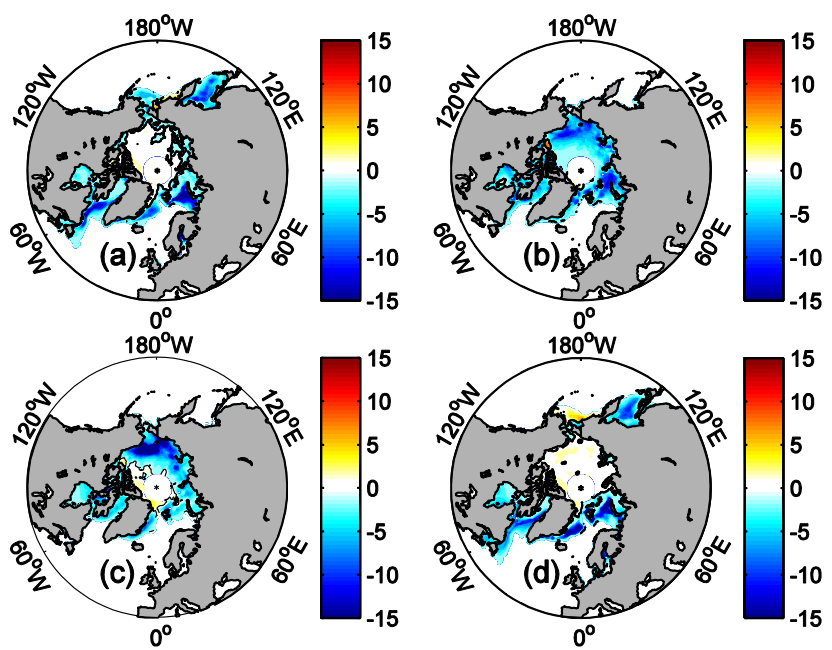

Figure 8. Linear trends (units: \% per decade) of satellite-observed Arctic sea ice concentration during 1979-2005. (a) Spring, (b) summer, (c) autumn, and (d) winter.

and CMIP5-simulated SIE in autumn have the largest decreasing trend. The CMIP5-simulated difference between the summer and autumn SIE-decreasing trend is, however, larger than that of the observations. The main reason is that CMIP5-
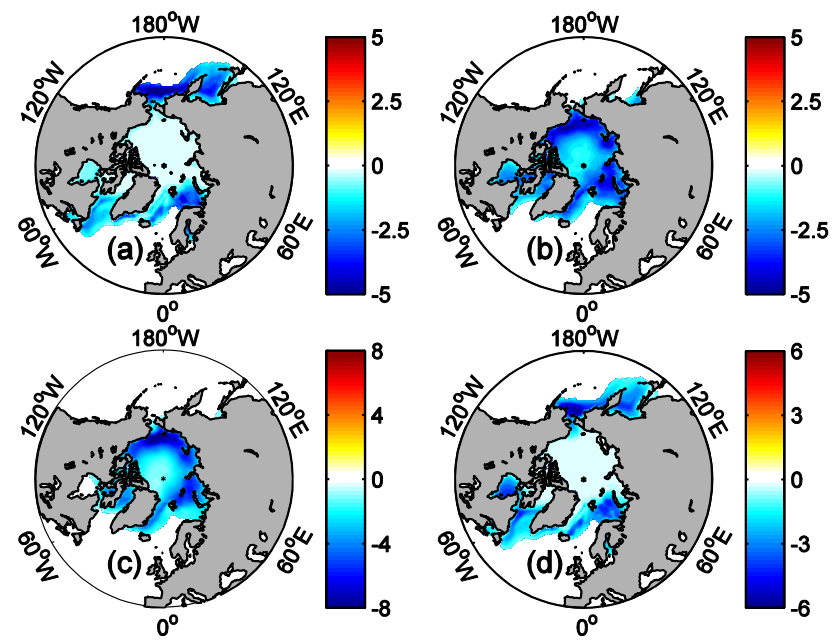

Figure 9. Linear trends (units: \% per decade) of CMIP5-simulated Arctic sea ice concentration during 1979-2005. (a) Spring, (b) summer, (c) autumn, and (d) winter.

simulated SIE has a small reduction in summer, especially in July (Fig. 7). The satellite-observed SIE decreasing rate is $5.22 \%$ per decade in July, while the CMIP5-simulated decreasing rate is $3.54 \%$ per decade. The largest decreasing rate is in September; the observed trend is $-8.61 \%$ per decade, and the simulated trend is $-8.46 \%$ per decade.

Figures 8 and 9 show that the spatial patterns of CMIP5simulated SIC reduction rate are consistent with the observations from 1979 to 2005, but the decreasing rates are smaller than the observations. In spring and winter, the observed decreasing SIC is mainly in the Okhotsk Sea, Baffin Bay, Greenland Sea and Barents Sea; CMIP5-simulated decreasing SIC is also in these regions. In summer and autumn, the main decreasing SIC is in the Chukchi Sea, the Barents Sea, and the Kara Sea (Figs. 8 and 9), and CMIP5 MME SIC has similar characteristics. However, CMIP5 simulations have larger trends in the central Arctic Ocean. 

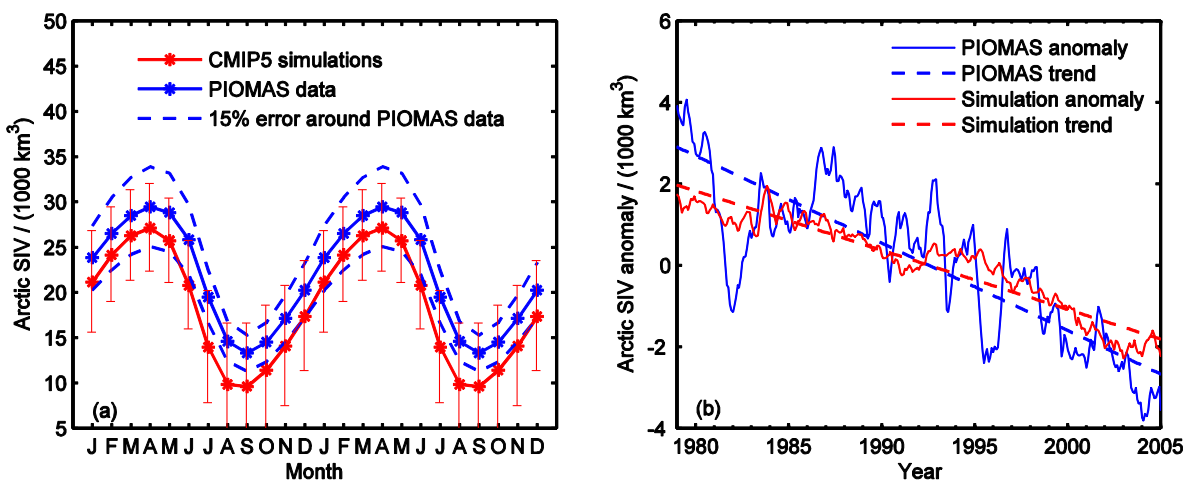

Figure 10. Climatology (a), anomaly and linear trend (b) of PIOMAS and CMIP5-simulated Arctic sea ice volume during 1979-2005. Two annual cycles are plotted in (a). The error bar is the range of 1 standard deviation.

Compared with PIOMAS sea ice thickness, the main problems of CMIP5 simulations are smaller Arctic SIV all year round and an overly large model spread (Fig. 10). In spring, the Arctic has the largest SIV. Long-term mean PIOMAS SIV is at its maximum in April at $29.5 \times 10^{3} \mathrm{~km}^{3}$, and the corresponding CMIP5 MME is $27.1 \times 10^{3} \mathrm{~km}^{3}$. Long-term mean PIOMAS SIV reaches its minimum in September at $13.3 \times 10^{3} \mathrm{~km}^{3}$, and the corresponding CMIP5 MME is $9.6 \times 10^{3} \mathrm{~km}^{3}$. Amplitude of SIV from PIOMAS is $16.17 \times 10^{3} \mathrm{~km}^{3}$, and CMIP5 MME can give good amplitude of SIV with $17.50 \times 10^{3} \mathrm{~km}^{3}$. CMIP5 SIV model spread is also very large: 1 standard deviation for each month is greater than $15 \%$ of GIOMAS SIV. CanESM2 has the smallest SIV of $9.97 \times 10^{3} \mathrm{~km}^{3}$, and CMCC$\mathrm{CM}$ has the largest SIV of $33.01 \times 10^{3} \mathrm{~km}^{3}$. Figure S8 shows that sea ice thickness in BCC-CSM1-1-M, CanCM4, CanESM2, GFDL-CM2p1, GISS-E2-H, GISS-E2-H-CC, GISS-E2-R, GISS-E2-R-CC, MIROC4h, MIROC-ESM, and MIROC-ESM-CHEM is significantly undervalued. Sea ice thickness in CESM1-WACCM, CMCC-CESM, CMCC-CM, FGOALS-g2, IPSL-CM5B-LR, NorESM1-M, NorESM1$\mathrm{ME}$ is significantly overvalued. Based on PIOMAS, the linear trend of Arctic SIV during 1979-2005 is $-2.14( \pm 0.14) \times 10^{3} \mathrm{~km}^{3} \mathrm{decade}^{-1}$. CMIP5 MME trend has the same sign but with smaller value, at -1.45 $( \pm 0.05) \times 10^{3} \mathrm{~km}^{3} \mathrm{decade}^{-1}$. Unlike most of CMIP5 models, CESM1-WACCM SIV has a slight positive trend during 1979-2005. The reason may be CESM1-WACCM SIV has large variability $\left(2.07 \times 10^{3} \mathrm{~km}^{3}\right)$, and its internal variability is not in phase with the natural observed variability.

\section{Conclusions and discussion}

The first ensemble realizations of the 49 CMIP5 historical simulations are evaluated in terms of the performance of sea ice. Our results show that the Arctic sea ice simulations are better than the Antarctic sea ice simulations, and SIE simulations are better than SIV simulations. CMIP5 MME SIV is too little in winter and spring, because the sea ice thickness in CMIP5 models is too thin in winter and spring compared with the GIOMAS and PIOMAS data. In the Antarctic, MME can reproduce good mean state and monthly amplitude for SIE, but for SIV MME mean state and amplitude are smaller. In the Arctic, MME can reproduce good mean state and monthly amplitude for both SIE and SIV. CMIP5 simulations have very different variability (indicated by standard deviation of detrended monthly SIE and SIV) for different models. From Tables 1 and 2 we can conclude that the performance of each model is different. For the Antarctic, ACCESS1.0, BCC-CSM1.1, CESM1-CAM5-1-FV2, CMCCCM, EC-EARTH, GISS-E2-H-CC, MIROC-ESM, MIROCESM-CHEM, MRI-CGCM3, MRI-ESM1 and NorESM1$M$ can give better SIE and SIV mean state. For the Arctic, ACCESS1.3, CCSM4, CESM1-BGC, CESM1-CAM5, CESM1-CAM5-1-FV2, CESM1-FASTCHEM, EC-EARTH, MIROC5, NorESM1-M and NorESM1-ME can give better mean state of SIE and SIV. The Arctic SIE linear trends of BNU-ESM, CanCM4, CESM1-FASTCHEM, EC-EARTH, GFDL-CM2p1, HadCM3, HadGEM2-AO, MIROC-ESMCHEM, MPI-ESM-MR and MRI-ESM1 are closed to the observations.

Both satellite-observed Antarctic SIE and GIOMAS Antarctic SIV show increasing trends over the period of 1979-2005, but CMIP5 MME Antarctic SIE and SIV have decreasing trends. Only eight models' SIE and eight models' SIV show increasing trends. Can these few CMIP5 models reproduce the correct Antarctic sea ice trend? If we use these eight CMIP5 models to plot Antarctic SIC trends (not shown) as in Fig. 4, we will find that these eight CMIP5 model mean SIC trends have different spatial patterns with the observations (Fig. 3), although their model mean SIE and SIV have increasing trends. Satellite-observed Antarctic SIE has increased trends, but when we use the satellite-observed sea ice record, we should also keep in mind that it may also have a large degree of uncertainty. Eisenman et al. (2014) point 


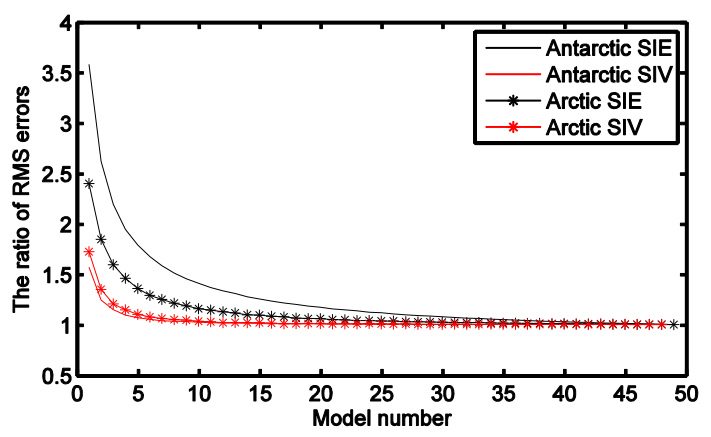

Figure 11. The ratio of SIE and SIV RMS errors between the errors calculated using different number of CMIP5 models and the error calculated using all 49 CMIP5 models.

out that sensor transition may cause a substantial change in the long-term trend.

We can see that the CMIP5 MME does a good job in terms of climatological mean, but their inter-model spread is large. The number of models used in published studies is usually less than the total CMIP5 models. How many models can give as similarly good simulations as all the available CMIP5 models do? We first choose the CMIP5 models randomly. The model number changes from 1 to 49 . We then calculate the SIE and SIV RMS errors between MME and observations or GIOMAS and PIOMAS data sets. For each fixed model number, we choose these models randomly at many different times, and then calculate the mean of the RMS errors. Figure 11 shows the ratio of SIE and SIV RMS errors between the errors calculated using different number of CMIP5 models and the errors calculated using all 49 CMIP5 models. We can see that the model errors decrease quickly as the model number increases; and the more models we use, the smaller error we have. For a fixed model number, the ratios of SIE are larger than the ratios of SIV, and Antarctic SIE has the largest ratio. When the model number is greater than 30 , the model errors do not change much anymore. If we choose a criterion of RMS error larger than $15 \%$ of all the model RMS error, the model number of 22 is the critical number for Arctic SIE. It means that more than 22 CMIP5 models should give similar MME as all 49 CMIP5 models.

In this study, satellite observations, PIOMAS and GIOMAS data during the period of 1979-2005 are used to assess the sea ice simulations from CMIP5 models. We always expect the models can capture the observed trends during this period. But we should note that simulations without data assimilation are always out of phase with the natural variability seen in the observations. So the differences between simulations and observations can either be due to model biases or natural climate variability (Stroeve et al., 2014).

\author{
The Supplement related to this article is available online \\ at doi:10.5194/tc-9-399-2015-supplement.
}

Acknowledgements. Satellite-observed sea ice concentration data are provided by http://nsidc.org/data/seaice/, sea ice extent are from ftp://sidads.colorado.edu/DATASETS/NOAA/G02135/, GIOMAS sea ice date are downloaded from http://psc.apl.washington.edu/ zhang/Global_seaice/index.html, and PIOMAS sea ice date are from http://psc.apl.washington.edu/wordpress/research/projects/ arctic-sea-ice-volume-anomaly/. CMIP5 sea ice simulations are downloaded from http://pcmdi9.1lnl.gov/esgf-web-fe/. The authors thank the above-listed data providers. This work is supported by the National Basic Research Program of China (973 Program) under Grant 2010CB950500, National Natural Science Foundation of China (Grant Numbers 41406027 and 41306206), the Project of Comprehensive Evaluation of Polar Areas on Global and Regional Climate Changes (CHINARE2014-04-04, CHINARE2014-04-01, and CHINARE2014-01-01), and Polar Strategic Research Foundation of China (20120103).

Edited by: J. Stroeve

\section{References}

Cavalieri, D. J., Parkinson, C. L., Gloersen, P., and Zwally, H.: Sea Ice Concentrations from Nimbus-7 SMMR and DMSP SSM/ISSMIS Passive Microwave Data, NASA DAAC at the National Snow and Ice Data Center, Boulder, Colorado, USA, 1996.

Cavalieri, D. J., Gloersen, P., Parkinson, C. L., Comiso, J. C., and Zwally, H. J.: Observed hemispheric asymmetry in global sea ice changes, Science, 278, 1104-1106, 1997.

Cavalieri, D. J., Parkinson, C. L., and Vinnikov, K. Y: 30Year satellite record reveals contrasting Arctic and Antarctic decadal sea ice variability, Geophys. Res. Lett., 30, 1970, doi:10.1029/2003GL018031, 2003.

Eisenman, I., Meier, W. N., and Norris, J. R.: A spurious jump in the satellite record: has Antarctic sea ice expansion been overestimated?, The Cryosphere, 8, 1289-1296, doi:10.5194/tc-8-12892014, 2014.

Kurtz, N. and Markus, T.: Satellite observations of Antarctic sea ice thickness and volume, J. Geophys. Res., 117, C08025, doi:10.1029/2012JC008141, 2012.

Liu, J., Song, M., Horton, R. M., and Hu, Y.: Reducing spread in climate model projections of a September ice-free Arctic, P. Natl. Acad. Sci., 110, 12571-12576, 2013.

Mahlstein, I., Gent, P. R., and Solomon, S.: Historical Antarctic mean sea ice area, sea ice trends, and winds in CMIP5 simulations, J. Geophys. Res.-Atmos., 118, 5105-5110, 2013.

Massonnet, F., Fichefet, T., Goosse, H., Bitz, C. M., PhilipponBerthier, G., Holland, M. M., and Barriat, P.-Y.: Constraining projections of summer Arctic sea ice, The Cryosphere, 6, 13831394, doi:10.5194/tc-6-1383-2012, 2012.

Polvani, L. M. and Smith, K. L.: Can natural variability explain observed Antarctic sea ice trends? New modeling evidence from CMIP5, Geophys. Res. Lett., 40, 3195-3199, 2013.

Stroeve, J., Barrett, A., Serreze, M., and Schweiger, A.: Using records from submarine, aircraft and satellites to evaluate climate 
model simulations of Arctic sea ice thickness, The Cryosphere, 8, 1839-1854, doi:10.5194/tc-8-1839-2014, 2014.

Stroeve, J. C., Kattsov, V., Barrett, A., Serreze, M., Pavlova, T., Holland, M., and Meier, W. N.: Trends in Arctic sea ice extent from CMIP5, CMIP3 and observations, Geophys. Res. Lett., 39, L16502, doi:10.1029/2012GL052676, 2012.

Turner, J., Comiso, C., Marshall, G. J., Lachlan-Cope, T. A., Bracegirdle, T., Maksym, T., Meredith, M. P., Wang, Z., and Orr, A.: Non-annular atmospheric circulation change induced by stratospheric ozone depletion and its role in the recent increase of Antarctic sea ice extent, Geophys. Res. Lett., 36, L08502, doi:10.1029/2009GL037524, 2009.

Turner, J., Bracegirdle, T. J., Phillips, T., Marshall, G. J., and Hosking, J. S.: An Initial Assessment of Antarctic Sea Ice Extent in the CMIP5 Models, J. Climate, 26, 1473-1484, doi:10.1175/JCLID-12-00068.1, 2013.

Vaughan, D. G., Marshall, G. J., Connolley, W. M., Parkinson, C., Mulvaney, R., Hodgson, D. A., King, J. C., Pudsey, C. J., and Turner, J.: Recent rapid regional climate warming on the Antarctic Peninsula, Climatic Change, 60, 243-274, 2003.
Worby, A. P., Geiger, C. A., Paget, M. J., Van Woert, M. L., Ackley, S. F., and DeLiberty, T. L.: Thickness distribution of Antarctic sea ice, J. Geophys. Res.-Oceans, 113, C05S92, doi:10.1029/2007JC004254, 2008.

Xie, H., Tekeli, A. E., Ackley, S. F., Yi, D., and Zwally, H. J.: Sea ice thickness estimations from ICESat altimetry over the Bellingshausen and Amundsen Seas, 2003-2009, J. Geophys. Res.-Oceans, 118, 2438-2453, 2013.

Zhang, J. and Rothrock, D.: Modeling global sea ice with a thickness and enthalpy distribution model in generalized curvilinear coordinates, Mon. Weather Rev., 131, 845-861, 2003.

Zunz, V., Goosse, H., and Massonnet, F.: How does internal variability influence the ability of CMIP5 models to reproduce the recent trend in Southern Ocean sea ice extent?, The Cryosphere, 7, 451-468, doi:10.5194/tc-7-451-2013, 2013.

Zwally, H. J., Comiso, J. C., Parkinson, C. L., Cavalieri, D. J., and Gloersen, P.: Variability of Antarctic sea ice 1979-1998, J. Geophys. Res.-Oceans, 107, 9-1-9-19, 2002. 